OPEN ACCESS

Edited by:

Pilar Lacasa,

University of Alcalá, Spain

Reviewed by:

Bikash Koli Dey,

Hongik University, South Korea

Petar Radanliev,

University of Oxford, United Kingdom

${ }^{*}$ Correspondence:

Huifeng Zhang

zhanghf@ruc.edu.cn

Specialty section:

This article was submitted to

Personality and Social Psychology,

a section of the journa

Frontiers in Psychology

Received: 13 November 2020

Accepted: 19 April 2021

Published: 28 May 2021

Citation:

Sun $Y$ and Zhang H (2021) What Motivates People to Pay for Online

Sports Streaming? An Empirical Evaluation of the Revised Technology

Acceptance Model.

Front. Psychol. 12:619314.

doi: 10.3389/fpsyg.2021.619314

\section{What Motivates People to Pay for Online Sports Streaming? An Empirical Evaluation of the Revised Technology Acceptance Model}

\author{
Ye Sun and Huifeng Zhang * \\ The School of Journalism and Communication, Renmin University of China, Beijing, China
}

With the rapid development of Internet technology, sports media consumption is migrating toward streaming. The online streaming of sporting events has become the important way of copyrights holders to engage sports fans, especially young fans. Therefore, it is vital to understanding users' willingness to pay (WTP). Given that previous studies of the livestream sports broadcasts online have not dealt with users' payment intention, the originality of this study is that it explore users' motivation by combining information system research with the consumer demand theory. The study aimed to examine the factors that influence users' payment intention to stream online sports by using the extended Technology Acceptance Model (TAM). Data from questionnaires completed by 330 Chinese respondents determined how perceived usefulness, ease, enjoyment, and satisfaction, influence users' WTP. Satisfaction positively correlated with users' payment intentions, impacted WTP values, mediated ease of use. The analysis also revealed the necessity for broadcast platforms to improve satisfaction and to increase payment intentions.

Keywords: livestreaming, sports, perceived enjoyment, willingness to pay, technology acceptance model

\section{INTRODUCTION}

Consumers expect copyright owners to use various online platforms to distribute media effectively and to their smart-phones, laptops PCs, and other wireless streaming devices. It is clear that the COVID-19 further accelerate the digital transformation of sports industry. Due to postponement and cancellation of sports events, COVID-19 has deprive spectators, pushing copyrights owners to reshape and augment the digital users' experience in order to generate more revenue from online sports streaming. According to the survey of top opportunities to increase revenues in the sports industry, $89.3 \%$ of the respondents consider that enhancing digital media fan experience is the best way ( $\mathrm{PwC}, 2020)$. Online media are expected to be a significant source of revenue in the coming years (Liu and Peng, 2017). In contrast, livestream sports platforms face cyber risk, such data risk, cyber-crime and human error (Radanliev et al., 2020; Sheehan et al., 2021). To improve the experience of watching the sports events on the network platform, the online sports streaming medias adopt artificial intelligence technology, but it neglects the security of users' data and aggravate the cyber risk, which can easily lead to the leakage of users' data (Radanliev et al., 2020). Moreover, owing to the anonymity of the "bullet screen" service of the online sports streaming media, cyber-criminal organizations use the "bullet screen" to induce users to illegal websites, resulting in users' financial 
losses. Based on this, the development of network video platform has both opportunities and challenges. And there is a gap between the number of viewers who currently pay and those who do not. Hence, it is necessary to analyze the motivations of paying users.

Most studies on sports media subscriptions and subscribers have regarded the marketing strategy of online platforms (Evens et al., 2011; Hao, 2019), though few studies have focused on users' willingness to pay. This study extends the research scope from offline to online, from public sports programs to commercial sports media. From the perspective of influencing factors, recent researches about public sports program have shown about public that consumers' payment intentions are determined by two kinds of variables, individual characteristic variables (e.g., age, income, gender), psychological variables (e.g., identification, trust, satisfaction) (see Table 1). However, technology readiness level that have not been explored in the previous study is essential to network live streaming media. This study attempts to explored technology readiness level and other internal motivational factors that affect users' willingness to pay (WTP) for online sports streaming.

Reviewing the previous literatures, it was found that WTP has been employed to study consumers' payment intention, while TAM has been utilized to explain the influential factors of users' behavioral intentions. Thus, combining the TAM with WTP can answer the question, "What motivates people pay for online sports events?" Two external variables about technology readiness level in the original TAM, perceived usefulness and perceived ease of use as related to payment behavioral intention (Arogundade et al., 2016; Vladova et al., 2021), but few prior studies confirmed internal variables, such as perceived enjoyment as bearing influence on a consumer's willingness to pay (Joeckel and Bowman, 2012).

Congruent with these previous studies, this study evaluates the relationship between these two external variables and users' willingness to pay. The present research introduces two internal variables-perceived enjoyment and perceived satisfaction - to further examine the determinants of consumers' willingness to pay for live sports online. The new evaluation model is appropriate for identifying the factors affecting users' willingness to pay to view sports matches online and provides valuable marketing information to the online platforms for developing their own digital media distribution strategy to satisfy consumer demands.

\section{THEORETICAL BACKGROUND AND PRIOR STUDY}

\section{Theory of the Technology Acceptance Model}

The technology acceptance model (TAM) is the most frequently adopted theory in explaining technology usage (Princi and Krämer, 2020). Due to the simple construction of TAM, it has been widely adopted to investigate users' acceptance of different kinds of technologies.

Adapted from the theory of reasoned action (TRA), TAM was introduced by Davis (1989) to specifically explain the behavior of users' technology acceptance. In the original TAM, five specific variables, including perceived usefulness, perceived ease of use, attitude toward using, behavioral intention to use, and actual system use, were factors developed to explain technology acceptance. Both perceived usefulness and perceived ease of use, were the dominant determinants of users' attitudes toward using new technology (Davis et al., 1989). The TAM also suggested that perceived usefulness and users' attitude toward directly and significantly influence behavioral intention to use (Davis et al., 1989). In addition, it posits that users' actual use of a new system or technology is mainly determined by behavioral intention. Understanding why people accept or reject a new system or technology has been one of the most popular subjects in recent research (Abdullah et al., 2016; Lemay et al., 2018). However, prior studies have produced no reliable evidence to indicate a significant relationship between perceived usefulness and an attitude toward using a new technology (Rafique et al., 2020; Lin et al., 2021). Congruent with these studies, the attitude was removed from the original TAM to confirm the relationship between external variables (e.g., perceived usefulness and perceived ease of use) and behavioral intention to use in the present research (Rauniar et al., 2014; Abed, 2016). Instead, we added an intrinsic motivation variable-perceived enjoyment-to develop a more convincing explanation of what might affect the behavioral intention of the hedonic system (Dickinger et al., 2008; Vladova et al., 2021). In addition, satisfaction was introduced to TAM as a direct determinant of behavioral intention.

The purpose of the TAM is to provide a scientific, rational, and efficient model to explain what motivates users to accept or reject a new technology. Based on the previous theoretical and empirical literature, this study adds two new variablesperceived enjoyment and satisfaction - to the research model in order to quantify users' willingness to pay for livestream sports broadcast platforms.

\section{Previous Study of the Willingness to Pay}

Willingness to pay (WTP) originated in the study of economic impacts on consumers. WTP suggests the value of a product or service to a consumer is equivalent to the maximum price a consumer is willing to pay for that product or service (Kalish and Nelson, 1991). In recent studies, WTP theory has been applied to public goods and commercialized goods, including sports teams (Wicker et al., 2016), sporting events (Li and Yang, 2019), and media products (Zhang and Deng, 2018).

According to WTP, two factors determine the extent to which consumers are willing to pay for products or services. The first factor of WTP investigates the consumer's payment intention. The second factor of WTP considers consumer's WTP value in terms of the consumer's willingness to pay a premium price (Tudoran and Olsen, 2017). Integrating the TAM into the evaluation of consumer motivation has advanced researchers' abilities to study the factors that influence consumers' willingness to pay (Arogundade et al., 2016).

In regard to WTP, payment intention acts as behavioral intention in the modified TAM. However, the variable of actual use can be replaced by the WTP value (Arogundade 
TABLE 1 | Contributions of previous Johnson authors.

\begin{tabular}{|c|c|c|c|c|}
\hline \multirow[t]{2}{*}{ References } & \multirow[t]{2}{*}{ Research subject } & \multicolumn{3}{|c|}{ Influencing factors } \\
\hline & & $\begin{array}{l}\text { Demographic } \\
\text { variables }\end{array}$ & $\begin{array}{l}\text { Psychological } \\
\text { variables }\end{array}$ & $\begin{array}{l}\text { Technical } \\
\text { variables }\end{array}$ \\
\hline Johnson et al. (2007) & Amateur sport programs & YES & e.g., moral norms & NA \\
\hline Wicker (2011) & Non-profit sports clubs & YES & NA & NA \\
\hline Bakkenbüll and Dilger (2018) & World cup success & YES & $\begin{array}{l}\text { e.g., identification, personal } \\
\text { importance, national importance }\end{array}$ & NA \\
\hline Funahashi and Mano (2015) & Elite sport policy & YES & $\begin{array}{l}\text { e.g., benefit perception, risk } \\
\text { perception, Trust, knowledge }\end{array}$ & NA \\
\hline Wicker et al. (2016) & Sporting success & NA & $\begin{array}{l}\text { e.g., happy, reputation, talking about } \\
\text { the team }\end{array}$ & NA \\
\hline Zawadzki (2016) & Mega sports events & YES & e.g., national pride, intangible costs & NA \\
\hline Frick and Wicker (2017) & World championships & YES & $\begin{array}{l}\text { e.g., expectations, consumption } \\
\text { capital, happy }\end{array}$ & NA \\
\hline Wicker et al. (2017) & Mega sports events & YES & $\begin{array}{l}\text { e.g., identify, proud, happy, } \\
\text { reputation, role models, interest }\end{array}$ & NA \\
\hline Wicker et al. (2018) & Sports clubs & YES & $\begin{array}{l}\text { e.g., identification, } \\
\text { satisfaction }\end{array}$ & NA \\
\hline De Boer et al. (2019) & Mega sports events & YES & NA & NA \\
\hline Wicker and Frick (2020) & Elite athlete development & YES & $\begin{array}{l}\text { e.g., life satisfaction, } \\
\text { identification, role models, happy }\end{array}$ & NA \\
\hline Thormann and Wicker (2021) & Non-profit sport clubs & YES & $\begin{array}{l}\text { e.g., environmental consciousness, } \\
\text { well-being }\end{array}$ & NA \\
\hline This Paper & Online sports streaming & YES & $\begin{array}{l}\text { e.g., satisfaction, } \\
\text { perceived enjoyment }\end{array}$ & $\begin{array}{l}\text { e.g., perceived } \\
\text { usefulness, } \\
\text { perceived ease of use }\end{array}$ \\
\hline
\end{tabular}

NA, Not Applicable. The variables are not mentioned in the paper.

et al., 2016). Consistent with the findings of the original TAM (Zhao et al., 2020), the results of prior studies confirmed that perceived usefulness and perceived ease of use are significant determinants of payment intention. Besides, payment intention has a significant effect on the WTP value (Wicker et al., 2016).

Understanding why consumers are willing to pay for livestream sports broadcasts is essential for both providers and consumers. This study integrates the processes of the TAM and WTP model to establish an integrated model that can explain the factors that determine users' payment intention and result in a WTP value for livestream sports broadcasts.

\section{HYPOTHESES AND RESEARCH MODEL}

\section{Perceived Usefulness}

Drawing on the theory of reasoned action, perceived usefulness and perceived ease of use are regarded as the fundamental determinants of user behavior in the TAM (Davis et al., 1989). Streaming media is considered as a new and efficient service that could save users' time and effort (Alalwan et al., 2018). Thus, perceived usefulness is re-defined as "which a person believes that using streaming media devices would improve his or her working/living quality" (Yang and Lee, 2018).

A series of previous studies indicated that perceived usefulness is positively associated with behavioral intention (Persico et al., 2014; Kumar Kakar, 2017; Chen and Wu, 2020). Perceived usefulness mediates the relationship between perceived ease of use and intention (Park et al., 2007; Carranza et al., 2021). Based on the empirical support from prior research, this present study seeks to revalidate similar relationships in the context of payment for livestream sports subscriptions. Hence, the following hypotheses are proposed:

H1. Perceived usefulness will have a positive effect on users' intentions to purchase livestream sports broadcasts online.

H1A. Perceived usefulness will mediate the effect of perceived ease of use on users' intention to purchase livestream sports broadcasts online.

\section{Perceived Ease of Use}

The TAM emphasizes the role of perceived ease of use in behavioral intentions to use different kinds of systems. Perceived ease of use, in its original form, refers to "the degree to which a person believes that using a particular system would be free of effort (Davis et al., 1989)." Base on the definition, Users' perceived ease of use for streaming media refers to the degree to which users can easily operate the devices (Yang and Lee, 2018). It could be more complicated for users to watch sports events by streaming media than by traditional TV (Alalwan et al., 2018; Yang and Lee, 2018). A number of previous studies showed that perceived ease of use significantly and positively affected users' intentions (Alalwan et al., 2016; Zhao et al., 2020). Hence, the following hypothesis is proposed: 
H2. Perceived ease of use will have a positive effect on users' payment intention to livestream sports broadcasts online.

According to the TAM, perceived ease of use is directly linked to usefulness because the easier the system is to use, the more useful it can be (Davis et al., 1989). There is extensive research on various systems that provides evidence of the significance of perceived ease of use on perceived usefulness (Rauniar et al., 2014; Alalwan et al., 2016). Congruent with the previous studies of the original TAM, this study proposes the following hypothesis:

H2A. Perceived ease of use will have a positive effect on the perceived usefulness of livestream sports broadcasts online.

As an intrinsic motive, perceived enjoyment is influenced by perceived ease of use. Based on the definition of perceived ease of use, when the system is easy to use, users require less mental effort to use it, which may stimulate users' emotional feedback, ultimately increasing their subjective enjoyment of interacting with the system (Wang and Scheepers, 2012). As with the relationship between perceived ease of use and perceived usefulness, the easier the system is to use, the more enjoyable it can be (Van der Heijden, 2003). The results of numerous empirical studies provided evidence that perceived ease of use is an essential factor in determining users' enjoyment of using systems (Dickinger et al., 2008; Abed, 2016). As such, this study proposes:

H2B. Perceived ease of use will have a positive effect on perceived enjoyment of the livestream sports broadcasts online.

Drawing on the relationship between perceived ease of use and perceived usefulness, the easier the system is to use, the more satisfied users can be (Rahmi et al., 2018). Previous studies indicated that a positive relationship exists between perceived ease of use and satisfaction (Nagy, 2018). Hence, the following hypothesis is proposed:

H2C. Perceived ease of use will have a positive effect on users' satisfaction with livestream sports broadcasts online.

\section{Perceived Enjoyment}

To examine the effect of users' intrinsic motivation on technology acceptance, the TAM model introduces the concept of perceived enjoyment (Davis et al., 1992; Van der Heijden, 2003). Base on the previous study, perceived enjoyment in this study is defined as the extent to which watching livestream sports is perceived as enjoyable in its own right, apart from any performance consequence that may be anticipated (Abdullah et al., 2016). Perceived enjoyment becomes a key factor underlying user acceptance of hedonic systems.

Some studies conceived perceived enjoyment as an intrinsic motivation and tested the effect of perceived enjoyment on hedonic system usage, with products such as websites, online video platforms, and social media (Wang and Scheepers, 2012; Jung et al., 2018). These studies confirmed the mediating effect between perceived ease of use and behavioral intention of perceived enjoyment (Van der Heijden, 2003). The results confirmed that the intention to use a hedonic system is mostly influenced by enjoyment (Dickinger et al., 2008; Abed, 2016; Moghavvemi et al., 2017). Congruent with the previous literature, this study posited the following hypotheses:

H3. Perceived enjoyment will have a positive effect on the payment intention for livestream sports broadcasts online.

H3A. Perceived enjoyment will mediate the effect of perceived ease of use on users' intention to livestream sports broadcasts online.

\section{Satisfaction}

Marketing and customer psychology have developed the foundation for the philosophy in marketplace satisfaction. Satisfaction is defined as a rate to which products are able to meet customer expectations (Oliver, 1981). In addition, satisfaction is highly based on emotion (Liao et al., 2009; Lee and Lehto, 2013). In this study, satisfaction refers to the degree to which the actual performance of the livestream broadcast meets users' expectations. Significantly, satisfaction can be measured only after using the system or technology (Nagy, 2018).

A number of previous studies have prorated the TAM to apply satisfaction to previous research (Alraimi et al., 2015; Amin et al., 2020) and affirmed the effect of satisfaction on behavioral intention, either directly or indirectly, through perceived ease of use (Dehghan et al., 2012; Alraimi et al., 2015). Hence, the following hypotheses are proposed:

H4. Satisfaction will have a positive effect on users' payment intention to livestream sports broadcasts online.

H4A. Satisfaction will mediate the effect of perceived ease of use on users' intention to purchase or subscribe to livestream sports broadcasts online.

\section{Willingness to Pay}

Willingness to pay is described as a customer's inclination to pay the maximum amount for a product or service (Tudoran and Olsen, 2017). There are two stages of willingness to pay, including payment intention and WTP values. If products or services satisfy customers' intentions and the price is lower than the customers' WTP values, then the customers will buy the products or services. Thus, there is a direct connection between payment intention and WTP values (Castellanos et al., 2011; Wicker et al., 2016). Based on the previous studies, this study hypothesizes:

H5. Users' payment intention to buy or subscribe to livestream sports broadcasts online will have a positive effect on WTP values.

\section{Summary of Study Goals}

Although livestream network platforms have become an inevitable trend in sports broadcasting, the factors that affect users' willingness to pay for the new services are not yet clear. By integrating the TAM with the WTP, this study considered that perceived usefulness and perceived ease of use in the original TAM would directly relate to intention to pay. New variables (perceived enjoyment and satisfaction) were introduced to modify the TAM to test the determinants of pay intention for livestream sports platforms, while the relationship between 
perceived usefulness and perceived ease of use remained. Users with a high degree of perceived ease of use are expected to increase their satisfaction with the platforms, while perceived ease of use is expected to influence perceived usefulness. In addition, it is hypothesized that users who handle the livestream sports platforms easily, will find them to be more enjoyable. Perceived usefulness, perceived enjoyment, and satisfaction are expected to mediate between perceived ease of use and payment intention. Based on the analysis thereof, the full conceptual model is illustrated in Figure 1.

\section{METHOD}

\section{Data Collection}

To protect the privacy of participants, the data were collected by distributing online-questionnaires in China. All questionnaires were using an anonymous survey. The study was approved by the Institutional Review Board of the Renmin University School of Journalism and Communication.

The significant premise of variables in this study was that users have previously watched sports events through network broadcast platforms, and therefore, all the participants were first asked, whether they had ever used livestream broadcast platforms to watch sports events. If their answer was "no" they did not continue with the survey and were excused from the study. Respondents who answered, "yes," were asked to participants in the survey. In total, 377 individuals responded to the onlinequestionnaires, and 330 (87.5\%) of them successfully completed all of the scales.

According to the demographic data, $15.8 \%$ of the respondents were females, and $84.2 \%$ were male. In terms of respondents' ages, 26-34 years-old accounted for the highest proportion, reaching $48.8 \%$ of the total sample. Individuals aged 19-25 comprised of $33.3 \%$, followed by $35-44$-year-olds, at $14.8 \%$. Respondents in this study under the age of $19(0.6 \%)$ and over the age of $45(2.4 \%)$ accounted for the lowest percentages. Regarding educational backgrounds, the largest group was comprised of undergraduates $(67.7 \%)$, followed by high school graduates (17.9\%), then postgraduates at $11.8 \%$, followed by doctoral students representing only $2.7 \%$ of the sample. None of the respondents were educated at less than high school graduation.

\section{Measure}

\section{Perceived Usefulness}

Using a seven-point Likert scale ( $1=$ strongly disagree, 7 $=$ strongly agree), three items from Davis et al. (1989) and Dickinger et al. (2008) were introduced to measure users' perceived usefulness (e.g., "I find watching livestream sports broadcasts through the Internet to be useful to me," "Livestream sports broadcasts are valuable for my communication effectiveness"). The measure's Cronbach alpha coefficient was 0.84 .

\section{Perceived Ease of Use}

Similar to the previous studies (Alalwan et al., 2018), perceived ease of use was measured by three items (e.g., "Watching livestream sports is clear and understandable," "I find it is easy to watch livestream sports through Internet") on a seven-point scale $(1=$ strongly disagree, $7=$ strongly agree). The threeitem perceived ease of use scale exhibited high levels of internal consistency $(\alpha=0.84)$.

\section{Perceived Enjoyment}

Items from Abdullah et al. (2016) were adapted for hedonic system usage to form a 3-item measure to assess users' perceived enjoyment (e.g., "I have fun watching livestream sports broadcasts on the computer," "I find watching livestream sports online enjoyable"). The items were answered on a 7 point Likert scale, with higher scores reflecting greater perceived

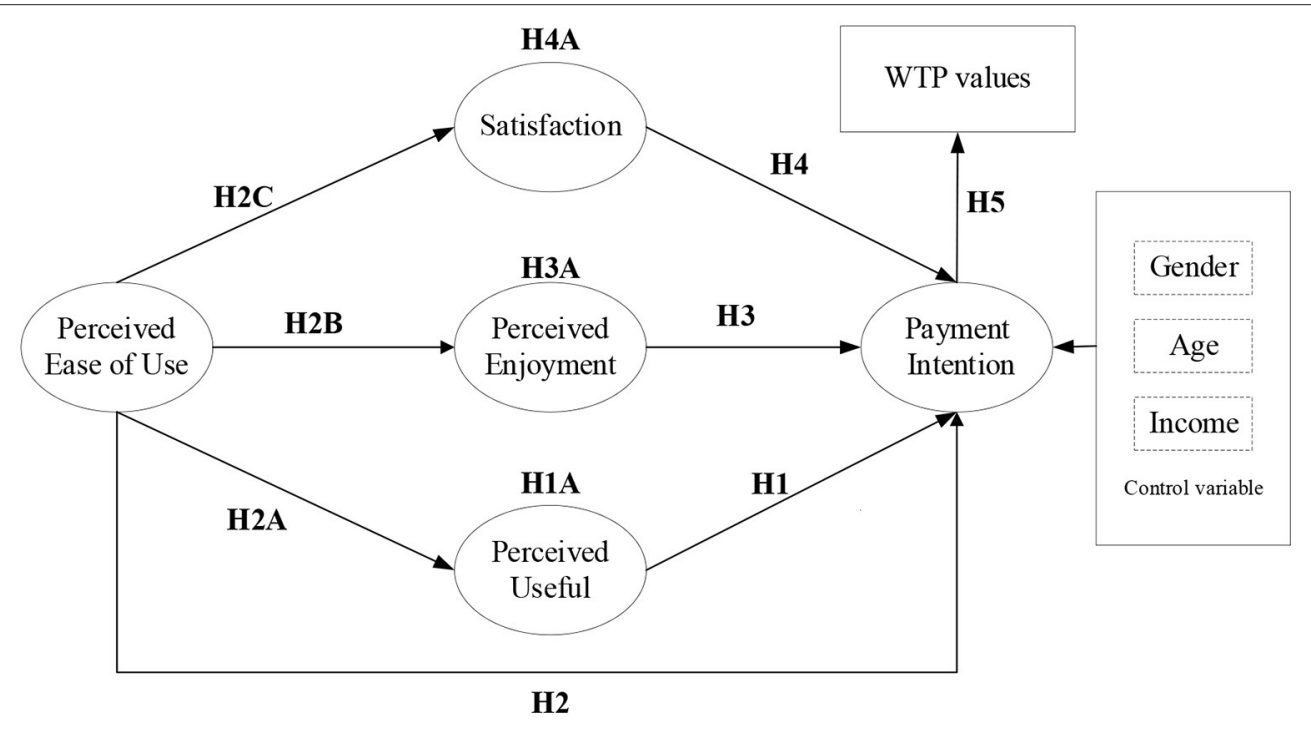

FIGURE 1 | Conceptual model. 
enjoyment. The perceived enjoyment exhibited high internal consistency $(\alpha=0.86)$.

\section{Satisfaction}

Satisfaction is regarded as consumer' overall evaluation when they find that products or services meet or exceed their positive expectations (Santini et al., 2018; Chung et al., 2020). Therefore, degrees of satisfaction may be influenced by all components of a service or product (Miranda et al., 2018). Based on a previous study (Zhang et al., 2006), three items were developed specifically for this study to assess users' satisfaction with livestream sports broadcasts (e.g., "I'm very satisfied with the commentary on the livestream sports broadcasts," "I'm very satisfied with the clarity of the livestream sports broadcasts."). All items were assessed on a seven-point Likert scale and combined in a scale $(\alpha=0.83)$.

\section{WTP and WTP Values}

Drawing on previous studies (Arogundade et al., 2016), payment intention was assessed by three items (Park et al., 2007; Abdullah et al., 2016). The three-item payment intention scale (e.g., "Given that I had access to pay for live sports online, I predict that I would pay for it," "I plan to pay for live sports online in the future") had high internal consistency ( $\alpha=0.85$ ). In addition, respondents about their maximum WTP: "Being more explicit, if you were willing to pay for livestream sports on the internet, what is the maximum monthly rate you would be willing to pay?"

\section{RESULTS}

Structural equation modeling (SEM) is the most efficient technique for estimating a series of separate multiple regressions (Hair et al., 2009). SEM primarily consists of two components; the measurement model and the structural model. It is common practice to adopt SEM for analyzing the cause-effect relationship between latent constructs in the study of TAM (Lemay et al., 2018). All calculations were completed by Mplus 8.3 software. To verify that scales represented the intended constructs, the measurement model was fitted to the data, using confirmatory factor analysis (see Table 2).

As shown in Table 3, the AVE for all variables in this study are above the recommended value of 0.5 and reach above 0.6 . Therefore, convergent validity is satisfactory. The bold number on the diagonal are the square of the AVE. And all the bold numbers $(0.803,0.779,0.826,0.797,0.810)$ exceeded the latent construct's highest correlation with any other latent construct, thus demonstrating that the underlying variables exhibited the property of discriminant validity.

The model fit indices were good (see Table 4; $\chi=282.875$, df $=142, \chi / \mathrm{df}=1.992, \mathrm{CFI}=0.943, \mathrm{TLI}=0.933, \mathrm{RMSEA}=0.055$, $\operatorname{SRMR}=0.083)$.

\section{Direct Effect on Payment Intention and WTP Values}

The SEM was conducted to test the proposed hypotheses. The findings indicated that three hypotheses regarding direct effect on payment intention and WTP values were supported, and two
TABLE 2 | Confirmatory factor analysis (CFA).

\begin{tabular}{|c|c|c|c|c|}
\hline Scales & Items & $\begin{array}{l}\text { Factor } \\
\text { loading }\end{array}$ & $P$-value & $\begin{array}{c}\text { Composite } \\
\text { reliability }\end{array}$ \\
\hline Perceived & PU1 & 0.778 & 0.000 & 0.840 \\
\hline \multirow[t]{2}{*}{ usefulness } & PU2 & 0.809 & 0.000 & \\
\hline & PU3 & 0.806 & 0.000 & \\
\hline Perceived & PE2 & 0.827 & 0.000 & 0.845 \\
\hline \multirow[t]{2}{*}{ ease of use } & PE3 & 0.751 & 0.000 & \\
\hline & PE4 & 0.829 & 0.000 & \\
\hline \multirow[t]{3}{*}{ Satisfaction } & SAT1 & 0.779 & 0.000 & 0.833 \\
\hline & SAT2 & 0.807 & 0.000 & \\
\hline & SAT3 & 0.785 & 0.000 & \\
\hline Perceived & PEJ1 & 0.774 & 0.000 & 0.865 \\
\hline \multirow[t]{2}{*}{ enjoyment } & PEJ2 & 0.757 & 0.000 & \\
\hline & PEJ3 & 0.937 & 0.000 & \\
\hline Payment & $\mathrm{Pl} 1$ & 0.806 & 0.000 & 0.852 \\
\hline \multirow[t]{2}{*}{ intention } & $\mathrm{Pl} 2$ & 0.852 & 0.000 & \\
\hline & PI3 & 0.772 & 0.000 & \\
\hline
\end{tabular}

hypotheses were not support at a statistically significant level (see Table 5).

H3 and H4 suggested that perceived enjoyment $(\beta=0.158$, $p<0.001)$, satisfactorily $(\beta=0.264, p<0.01$ ) had positive, significant, and direct effects on willingness to pay for livestream sports broadcasts on the internet. The fifth hypothesis, which examined the relationship between the willingness to pay and the WTP value: users' payment intention $(\beta=4.268, p<0.001)$ to purchase or subscribe to livestream sports online is positively related to the WTP value.

Perceived usefulness $(\beta=0.057, p=0.402)$ had no effect on users' payment intention to pay for or subscribe to livestream sports online. Similarly, there was no significant relationship between perceived ease of use $(\beta=-0.003, p=0.966)$ and the willingness to pay for livestream sports online. Thus, $\mathrm{H} 1$ and $\mathrm{H} 2$ were not supported.

\section{Direct Effect of Perceived Ease of Use}

Perceived ease of use, a fundamental external motivation variable, exhibited a crucial role in the study of willingness to pay for livestream sports broadcasts online. The result confirmed that perceived ease of use $(\beta=0.450, p<0.001)$ positively affected perceived usefulness, and supported H2A. Perceived ease of use $(\beta=0.378, p<0.001)$ had a positive and significant influence on users' perceived enjoyment, supporting H2B. H2C examined the relationship between perceived ease of use and satisfaction, suggesting users' perceived ease of use $(\beta=0.462, p<0.001)$ was positively associated with satisfaction.

\section{Moderating Role of Perceived Enjoyment and Satisfaction}

The finding of $\mathrm{H} 3 \mathrm{~A}$ indicated that perceived ease of use ( $\beta=$ $0.060, p<0.01$ ) had a significant, albeit indirect influence on the willingness to pay for livestream sports broadcasts online via the mediator of perceived enjoyment. H4A confirmed that 
TABLE 3 | Convergent validity and discriminant validity.

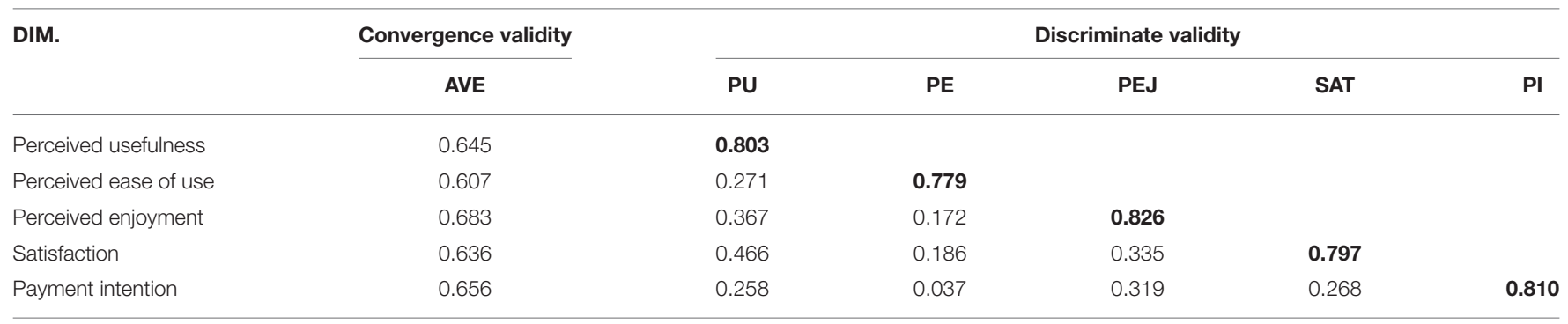

The bold number on the diagonal are the square of the AVE.

The bold number exceeded the latent construct's highest correlation with any other latent construct.

The AVE for all variables in this study are above the recommended value of 0.5 .

TABLE 4 | Model validation.

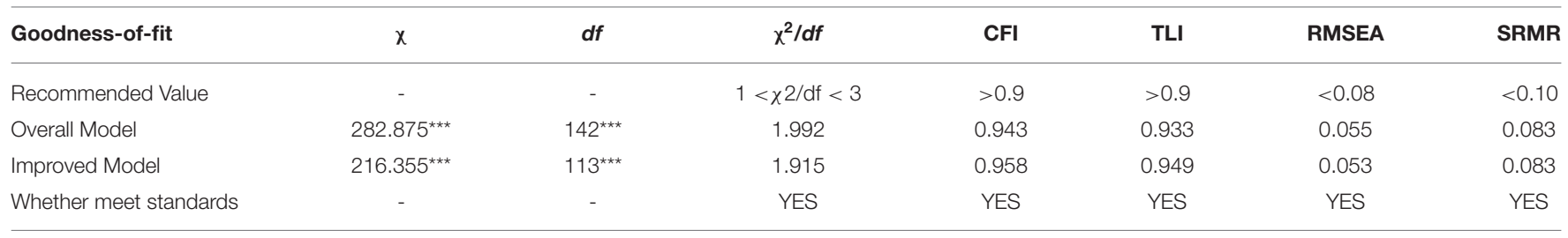

${ }^{\star \star \star} P<0.001$.

TABLE 5 | Hypotheses test.

\begin{tabular}{|c|c|c|c|c|c|c|c|c|}
\hline \multirow[t]{2}{*}{$\mathrm{DV} \rightarrow \mathrm{IV}$} & \multirow[t]{2}{*}{ Point estimate } & \multicolumn{2}{|c|}{$\begin{array}{l}\text { Product of } \\
\text { coefficient }\end{array}$} & \multicolumn{4}{|c|}{ BOOTSTRAP 1000 TIME 95\% CI } & \multirow{2}{*}{$P$-value } \\
\hline & & S.E. & $\mathbf{Z}$. & \multicolumn{2}{|c|}{ Bias corrected } & \multicolumn{2}{|c|}{ Percentile } & \\
\hline \multicolumn{9}{|c|}{ STANDARDIZED DIRECT EFFECTS } \\
\hline $\mathrm{H} 1: \mathrm{PU} \rightarrow \mathrm{PI}$ & 0.057 & 0.068 & 0.838 & -0.084 & 0.181 & -0.076 & 0.188 & 0.402 \\
\hline $\mathrm{H} 3: \mathrm{PEJ} \rightarrow \mathrm{PI}$ & 0.158 & 0.056 & 2.816 & 0.046 & 0.269 & 0.046 & 0.268 & ** \\
\hline $\mathrm{H} 4: \mathrm{SAT} \rightarrow \mathrm{PI}$ & 0.264 & 0.068 & 3.901 & 0.133 & 0.401 & 0.135 & 0.401 & $* \star \star$ \\
\hline H5: PI-WTP VALUES & 4.268 & 0.794 & 5.374 & 2.960 & 6.161 & 2.884 & 6.015 & $* \star *$ \\
\hline $\mathrm{H} 2 \mathrm{~A}: \mathrm{PE} \rightarrow \mathrm{PU}$ & 0.450 & 0.062 & 7.251 & 0.334 & 0.570 & 0.330 & 0.568 & 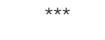 \\
\hline $\mathrm{H} 2 \mathrm{~B}: \mathrm{PE} \rightarrow \mathrm{PEJ}$ & 0.378 & 0.067 & 5.602 & 0.260 & 0.523 & 0.255 & 0.517 & 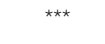 \\
\hline $\mathrm{H} 4 \mathrm{~A}: \mathrm{PE} \rightarrow \mathrm{SAT} \rightarrow \mathrm{PI}$ & 0.122 & 0.035 & 3.485 & 0.065 & 0.207 & 0.060 & 0.200 & 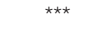 \\
\hline
\end{tabular}

${ }^{\star \star} P<0.001,{ }^{* \star *} P<0.01$.

satisfaction mediated the effect of perceived ease of use on users' intention to buy or subscribe to livestream sports online $(\beta=$ $0.122, p<0.001)$. The indirect effect of perceived ease of use on payment intention to buy or subscribe to livestream sports online by way of perceived usefulness was insignificant $(\beta=0.026, p=$ 0.402 ), rejecting H1A. The result model was shown on Figure 2.

Ruling out the variables that were insignificant to the willingness to pay for livestream sports online, the modified model vastly improved the evaluation processes of the former model $\left(\chi^{2}=216.355, \mathrm{df}=113, \chi^{2} / \mathrm{df}=1.915, \mathrm{CFI}=0.958, \mathrm{TLI}\right.$ $=0.949$, RMSEA $=0.053$, SRMR $=0.083$ ).

\section{DISCUSSION}

As live streaming of sporting events has become essential to fans and networks, understanding users' willingness to pay (WTP) has become vital. Combining perceived enjoyment, 


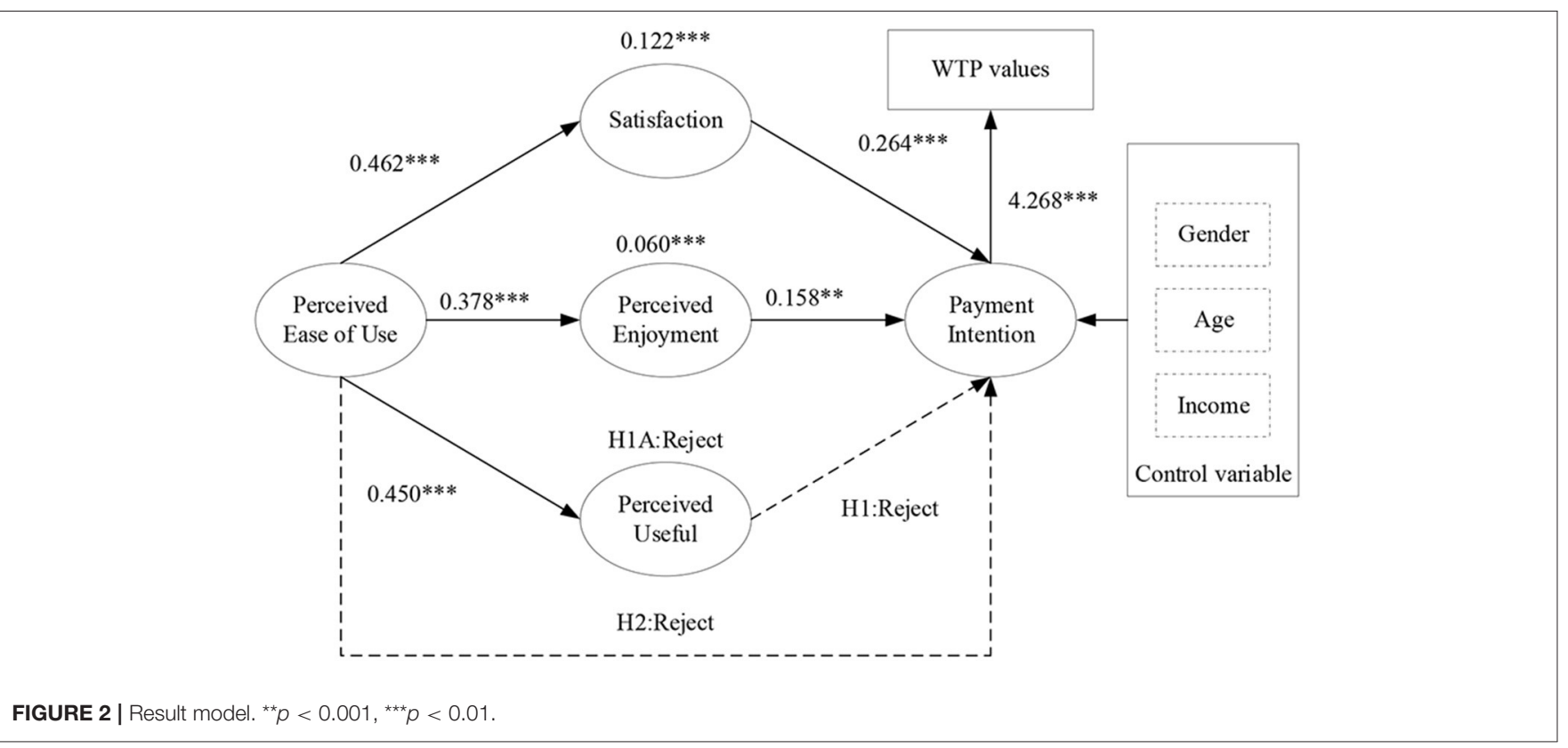

satisfaction with the Technology Acceptance Model (TAM), this study combined information system research with the consumer demand theory to examine factors influencing users' motivations to stream online sports. The rise of livestream sports broadcasts online is based on video streaming technologies, and required the establishment of a new model that could identify factors that influence users' payment intention based on external and internal motivations of technology acceptance. Perceived usefulness, perceived enjoyment, and satisfaction were positively related to the intention to pay for livestream sports broadcasts online. Congruent with previous studies (Van der Heijden, 2003; Abed, 2016), the results of this study supported the hypothesis that perceived enjoyment has a positive effect on users' payment intentions, and further confirmed that perceived enjoyment is the most significant factor in motivating payment intention. The impact of users' perceived enjoyment of livestream sports broadcasts for pay appear to be stronger when there are no free broadcast alternatives unavailable.

The direct connection between satisfaction and payment intention proved to be slightly stronger than the connection between perceived enjoyment and intention to pay for livestream sports broadcasts. The reason for the result might be that satisfaction is an emotional motivation based on repeated experiences. For hedonic systems, satisfied users are likely to be more significantly affected by positive emotional experiences that would lead to an increase in willingness to pay (Eisenbeiss et al., 2014; Tudoran and Olsen, 2017). Furthermore, satisfaction involves users' evaluations of clarity, speed, and commentary (Zhang et al., 2006) of livestream sports broadcasts in this study. The results suggested that users generated the willingness to pay primarily depending upon "their overall appraisal of how well they felt throughout the process of" using the service (Lee and Lehto, 2013).
Contrary to the hypothesis, the association between perceived ease of use and payment intention was not significant, which was consistent with the findings of previous research (Lee and Lehto, 2013). A reasonable explanation for the insignificant finding might be that it is very easy for users to watch sports events through live network platforms and realize real-time interaction with other spectators by "bullet comment." Another plausible explanation may be that ease of use proves to be irrelevant to users since instrumentality is prioritized over ease of use (Nagy, 2018). In sum, the users may not pay merely for the ease of use for livestream sports broadcasts. However, perceived enjoyment and satisfaction exerted complete mediating roles in the relationship between perceived ease of use and intention. The results of the mediation model were consistent with previous studies (Park et al., 2007; Pai and Huang, 2011), which suggested that the greater users' perceived ease of use to be, the more their satisfaction and perceived enjoyment improved, increasing their willingness to pay for livestream sports broadcasts.

Interestingly, perceived usefulness had no statistically significant effect on willingness to pay for livestream sports broadcasts. Previous studies on other hedonic products, such as an online game, confirmed the same finding ( $\mathrm{Wu}$ and $\mathrm{Zhou}$, 2017). A more plausible explanation would be that intrinsic motivation has a more dominant effect than extrinsic motivation, and especially in the hedonic system, extrinsic motivations may not exist (Wang and Scheepers, 2012). Users watch online sports events via the Internet during leisure time for fun, rather than for utilitarian-oriented usefulness.

\section{CONCLUSIONS}

This study not only enhanced the technology acceptance model by introducing two variables, perceived enjoyment (Vladova et al., 2021) and satisfaction (You et al., 2020; Liu et al., 2021) 
in the original TAM, but also integrate TAM and WTP to explicit the factors affecting users' payment intention to online sports streaming. It was confirmed that satisfaction has a positive effect on payment intention to buy or subscribe to livestream sports broadcasts. The findings of questionnaire indicated that all the respondents are willing to pay 16.1 yuan $(\$ 2.43)$ a month on average for online sports streaming. From the perspective of practice, this study provides significant evidence for the live football online platforms to take measures to improve user payment in the future, and the user experiences might be improved.

The significance of perceived enjoyment is emphasized in this study. Therefore, the business strategies of improving users' perceived enjoyment are an effective method to promote users' willingness to pay. In consideration of prior researches on hedonic products, it might be a good idea to promote live football online platforms with movies (Wang and Scheepers, 2012) or short video, as both of them have the same function with football live online. In addition, platforms should establish an interactive mechanism such as increasing the interest of "bullet comment" that users exchange ideas about football matches to strengthening interest and relax. There is no doubt that "bullet screen" play a vital role in meeting the entertainment needs of users (Tong and Zhao, 2019). However, it is worth noting that users can send "bullet comment" anonymously, which aggravates the cyber risk. In practice, cyber-crime is hidden in the "bullet screen"-criminal organizations induce users to access the illegal sports gambling websites, stealing private information of users by injecting malicious script code in web pages and causing the users' financial losses by network attacks.

Equally important, the study results confirm that satisfaction have a positive effect on payment intention. Therefore, how to improve user satisfaction to promote existing users' payment intention and attract more new users is one of the crucial issues for live sports online platforms. For instance, the platforms should invest more capital in technological innovation to improve digital images definition and operating speed, while the football commentators should enhance the specialized quality, change the language style to fit in with the needs of the internet. Due to the outright cancellation or postponement of major events impacted by COVID-19 outbreak, it increases the operating risks of online sports streaming. Therefore, streaming media can increase highlights, short-form content and athlete-generated content instead of live video content (PwC, 2020) to upgrade users' satisfaction during the lockdown.

Our findings indicate that users' intentions to pay for sports live online are influenced by perceived enjoyment and satisfaction. This provides a good starting point for discussion and further research. But the findings of study have to be seen in light of some limitations.

\section{REFERENCES}

Abdullah, F., Ward, R., and Ahmed, E. (2016). Investigating the influence of the most commonly used external variables of TAM on students' Perceived Ease of
First, the sample was cross-sectional, which limited the ability to make causal inference. It is a dynamic and continuous process form users' payment intention to their actual purchase behavior, and then to the continuous intention of purchasing a product (Liu et al., 2021). Longitudinal study is warranted for future studies.

Secondly, the analysis of WTP that all participants were users in China, the empirical findings of this study may not generalize to users in other nations. Different countries have different levels of development of the live football online platforms, while users in other countries have different payment behaviors. Future studies should expand the effective range of samples and the quantity with a wider geographical area (Tsai et al., 2020; Carranza et al., 2021).

Thirdly, cyber risk is the objective risk caused by streaming media technology. But whether users can perceive the cyber risk subjectively is also an important topic. Therefore, future research could categorize cyber risk of online sports streaming media into data risk, anonymous risk, cyber-crime risk, hacker risk (Sheehan et al., 2021) to explore users' perception of cyber risk, and further confirm the relationship between perceived cyber risk and willingness to pay of users.

\section{DATA AVAILABILITY STATEMENT}

The raw data supporting the conclusions of this article will be made available by the authors, without undue reservation.

\section{ETHICS STATEMENT}

The studies involving human participants were reviewed and approved by Renmin University of China, School of Journalism, and Communication, Institutional Review Board. The participants provided their informed consent to participate in this study.

\section{AUTHOR CONTRIBUTIONS}

All authors listed have made a substantial, direct and intellectual contribution to the work, and approved it for publication.

\section{FUNDING}

This work has been funded by Beijing Social Science Foundation under grant no. 20XCA005.

\section{ACKNOWLEDGMENTS}

We would like to express our appreciation to all the respondents who participant our study.

Use (PEOU) and Perceived Usefulness (PU) of e-portfolios. Comp. Hum. Behav. 63, 75-90. doi: 10.1016/j.chb.2016.05.014

Abed, S. S. (2016). An empirical examination of factors affecting continuance intention towards social networking sites. In: Conference 
on e-Business, e-Services and e-Society (Cham: Springer), 228-239. doi: 10.1007/978-3-319-45234-0_21

Alalwan, A. A., Baabdullah, A. M., Rana, N. P., Tamilmani, K., and Dwivedi, Y. K. (2018). Examining adoption of mobile internet in Saudi Arabia: extending TAM with perceived enjoyment, innovativeness and trust. Technol. Soc. 55, 100-110. doi: 10.1016/j.techsoc.2018.06.007

Alalwan, A. A., Dwivedi, Y. K., Rana, N. P., and Williams, M. D. (2016). Consumer adoption of mobile banking in Jordan: examining the role of usefulness, ease of use, perceived risk and self-efficacy. J. Enterpr. Inform. Manag. 29, 118-139. doi: 10.1108/jeim-04-2015-0035

Alraimi, K. M., Zo, H., and Ciganek, A. P. (2015). Understanding the MOOCs continuance: the role of openness and reputation. Comput. Educ. 80, 28-38. doi: 10.1016/j.compedu.2014.08.006

Amin, M. R. B. M., Masrani, S. A., and Piaralal, S. K. (2020). Integrating justice dimensions and expectation-confirmation model in measuring customer satisfaction and continuance intention in private higher education in Malaysia: a conceptual model. Int. J. Business Excellence. 20, 338-358. doi: 10.1504/ijbex.2020.106365

Arogundade, O. T., Mustapha, O., Ikotun, A. M., and Adejimi, A. O. (2016). An enhanced technology acceptance model to measure customers' willingness to pay more for secure software development. J. Natur. Sci. Eng. Techn. $15,103-118$.

Bakkenbüll, L. B., and Dilger, A. (2018). The willingness to pay for a German win of the 2014 FIFA World Cup in Brazil. Manag. Sport Leisure, 23, 174-188. doi: 10.1080/23750472.2018.1527714

Carranza, R., Díaz, E., Sánchez-Camacho, C., and Martín-Consuegra, D. (2021). ebanking adoption: an opportunity for customer value co-creation. Fron. Psych. 11, 4003. doi: 10.3389/fpsyg.2020.621248

Castellanos, P., García, J., and Sánchez, J. M. (2011). The willingness to pay to keep a Football club in a city: how important are the methodological issues? J. Sports Eco. 12, 464-486. doi: 10.1177/1527002510385301

Chen, C. L., and Wu, C. C. (2020). Students' behavioral intention to use and achievements in ICT-Integrated mathematics remedial instruction: case study of a calculus course. Comp. Educ. 145:103740. doi: 10.1016/j.compedu.2019.103740

Chung, M., Ko, E., Joung, H., and Kim, S. J. (2020). Chatbot e-service and customer satisfaction regarding luxury brands. J. Business Res. 117, 587-595. doi: 10.1016/j.jbusres.2018.10.004

Davis, F. D. (1989). Perceived usefulness, perceived ease of use, and user acceptance of information technology. MIS Q. 13, 319-340. doi: 10.2307/249008

Davis, F. D., Bagozzi, R. P., and Warshaw, P. R. (1989). User acceptance of computer technology: a comparison of two theoretical models. Manag. Sci. 35, 982-1003. doi: 10.1287/mnsc.35.8.982

Davis, F. D., Bagozzi, R. P., and Warshaw, P. R. (1992). Extrinsic and intrinsic motivation to use computers in the workplace 1. J. Appl. Soc. Psych. 22, 1111-1132. doi: 10.1111/j.1559-1816.1992.tb00945.x

De Boer, W. I., Koning, R. H., and Mierau, J. O. (2019). Ex ante and ex post willingness to pay for hosting a large international sport event. J. Sports Econ. 20, 159-176. doi: 10.1177/1527002518771445

Dehghan, A., Arjomand, P., Nayyeri, A., and Tabatabaey, M. (2012). "Offering a conceptual model of technology acceptance in e-Banking based on the customers' satisfaction and trust," in Computer Science and Convergence (Dordrecht: Springer), 415-424. doi: 10.1007/978-94-007-2792-2_40

Dickinger, A., Arami, M., and Meyer, D. (2008). The role of perceived enjoyment and social norm in the adoption of technology with network externalities. Europ. J. Inform. Syst. 17, 4-11. doi: 10.1057/palgrave.ejis.3000726

Eisenbeiss, M., Cornelißen, M., Backhaus, K., and Hoyer, W. D. (2014). Nonlinear and asymmetric returns on customer satisfaction: do they vary across situations and consumers? J. Acad. Market. Sci. 42, 242-263. doi: 10.1007/s11747-013-0366-1

Evens, T., Lefever, K., Valcke, P., Schuurman, D., and De Marez, L. (2011). Access to premium content on mobile television platforms: the case of mobile sports. Telem. Inform. 28, 32-39. doi: 10.1016/j.tele.2010.05.004

Frick, B., and Wicker, P. (2017). The value of alpine skiing to the Austrian population: a CVM study of the 2017 World Championships. Manag. Sport Leisure. 22, 414-427. doi: 10.1080/23750472.2018.1510742
Funahashi, H., and Mano, Y. (2015). Socio-psychological factors associated with the public's willingness to pay for elite sport policy: does risk perception matter? Manag. Sport Leisure. 20, 77-99. doi: 10.1080/13606719.2014.954860

Hair, J. F., Black, W. C., Babin, B. J., and Anderson, R. E. (2009). Multivariate Data Analysis, 7th Edn. Harlow: Pearson, 20.

Hao, Q. (2019). Innovation strategy of new sports media platform based on the improvement of user service experience-Take PP sports as an example. View Publ. 21,67-69. doi: 10.16491/j.cnki.cn45-1216/g2.2019.21.019

Joeckel, S., and Bowman, N. D. (2012). Graphics and gratification: exploring the link between technology and enjoyment in video games. J. Gam. Virtual Worlds 4, 25-43. doi: 10.1386/jgvw.4.1.25_1

Johnson, B. K., Whitehead, J. C., Mason, D. S., and Walker, G. J., (2007). Willingness to pay for amateur sport and recreation programs. Contemp. Econ. Policy 25, 553-564. doi: 10.1111/j.1465-7287.2007.00072

Jung, T. H., Dieck, M. C. T., and Chung, N. (2018). Determinants of hotel social media continued usage. Int. J. Contemp. Hosp. Manag. 30, 1152-1171. doi: 10.1108/ijchm-02-2017-0068

Kalish, S., and Nelson, P. (1991). A comparison of ranking, rating and reservation price measurement in conjoint analysis. Market Lett. 2, 327-335. doi: $10.1007 /$ bf00664219

Kumar Kakar, A. (2017). How do perceived enjoyment and perceived usefulness of a software product interact over time to impact technology acceptance? Interact Comp. 29, 467-480. doi: 10.1093/iwc/iwx006

Lee, D. Y., and Lehto, M. R. (2013). User acceptance of youtube for procedural learning: an extension of the technology acceptance model. Comp. Educat. 61, 193-208. doi: 10.1016/j.compedu.2012.10.001

Lemay, D. J., Morin, M. M., Bazelais, P., and Doleck, T. (2018). Modeling students' perceptions of simulation-based learning using the technology acceptance model. Clin. Simul. Nurs. 20, 28-37. doi: 10.1016/j.ecns.2018.04.004

Li,Y. J., and Yang, Q. (2019). Empirical research on the audience WTP of chinese professional soccer games and the influence factors. J. Xian Phys. Educat. Univer. 36, 49-57. doi: 10.16063/j.cnki.issn1001-747x.2019.03.008

Liao, C., Palvia, P., and Chen, J. L. (2009). Information technology adoption behavior life cycle: toward a Technology Continuance Theory (TCT). Int. J. Inform. Manag. 29, 309-320. doi: 10.1016/j.ijinfomgt.2009.03.004

Lin, Y. S., Chen, S. Y., Tsai, C. W., and Lai, Y. H. (2021). Exploring computational thinking skills training through augmented reality and AIoT learning. Front. Psych. 12:640115. doi: 10.3389/fpsyg.2021.640115

Liu, H., Shao, M., Liu, X., and Zhao, L. (2021). Exploring the influential factors on readers' continuance intentions of E-Book APPs: personalization, usefulness, playfulness, and satisfaction. Front. Psych. 12:262. doi: 10.3389/fpsyg.2021.640110

Liu, J., and Peng, S. (2017). Interaction and sports mobilization in online video sports live casting: a case of tencent 2017 "NBA all-star game." J. Wuhan Instit. Phys. Educ. 51, 18-22. doi: 10.3969/j.issn.1000-520X.2017.09.003

Miranda, S., Tavares, P., and Queiró, R. (2018). Perceived service quality and customer satisfaction: a fuzzy set QCA approach in the railway sector. $J$. Business Res. 89, 371-377. doi: 10.1016/j.jbusres.2017.12.040

Moghavvemi, S., Sharabati, M., Paramanathan, T., and Rahin, N. M. (2017). The impact of perceived enjoyment, perceived reciprocal benefits and knowledge power on students' knowledge sharing through Facebook. Int. J. Manag. Educ. 15, 1-12. doi: 10.1016/j.ijme.2016.11.002

Nagy, J. T. (2018). Evaluation of online video usage and learning satisfaction: an extension of the technology acceptance model. Int. Rev. Res. Open Distributed Learn. 19, 160-185. doi: 10.19173/irrodl.v19i1.2886

Oliver, R. L. (1981). Measurement and evaluation of satisfaction processes in retail settings. J. Retailing. 57, 25-48. Available online at: http://search.ebscohost. com/login.aspx?direct=true $\& \mathrm{db}=$ edsbig $\& A N=$ edsbig.A2050897\&lang=zhcn\&site=eds-live

Pai, F. Y., and Huang, K. I. (2011). Applying the technology acceptance model to the introduction of healthcare information systems. Technol. Forecast. Soc. Change 78, 650-660. doi: 10.1016/j.techfore.2010.11.007

Park, N., Lee, K. M., and Cheong, P. H. (2007). University instructors' acceptance of electronic courseware: an application of the technology acceptance model. J. Comp. Med. Commun. 13, 163-186. doi: 10.1111/j.1083-6101.2007. 00391.x 
Persico, D., Manca, S., and Pozzi, F. (2014). Adapting the Technology Acceptance Model to evaluate the innovative potential of e-learning systems. Comput. Hum. Behav. 30, 614-622. doi: 10.1016/j.chb.2013.07.045

Princi, E., and Krämer, N. C. (2020). Out of control-privacy calculus and the effect of perceived control and moral considerations on the usage of IoT healthcare devices. Front. Psych. 11:54. doi: 10.3389/fpsyg.2020.582054

PwC. (2020). Sports Industry: System Rebooting. Available online at: https://www. pwc.ch/en/insights/sport/sports-survey-2020.html

Radanliev, P., De Roure, D., Walton, R., Van Kleek, M., Montalvo, R. M., Santos, O., et al. (2020). Artificial intelligence and machine learning in dynamic cyber risk analytics at the edge. SN Appl. Sci. 2, 1-8. doi: 10.1007/s42452-020-03559-4

Rafique, H., Almagrabi, A. O., Shamim, A., Anwar, F., and Bashir, A. K. (2020). Investigating the acceptance of mobile library applications with an extended technology acceptance model (TAM). Comput. Educ. 145:103732. doi: 10.1016/j.compedu.2019.103732

Rahmi, B. A. K. I., Birgoren, B., and Aktepe, A. (2018). A meta analysis of factors affecting perceived usefulness and perceived ease of use in the adoption of e-learning systems. Turkish Online J. Distance Educ. 19, 4-42. doi: $10.17718 /$ tojde. 471649

Rauniar, R., Rawski, G., Yang, J., and Johnson, B. (2014). Technology acceptance model (TAM) and social media usage: an empirical study on Facebook. J. Enterprise Inform. Manag. 27, 6-30. doi: 10.1108/jeim-04-20120011

Santini, F. D. O., Ladeira, W. J., and Sampaio, C. H. (2018). The role of satisfaction in fashion marketing: a meta-analysis. J. Global Fashion Market. 9, 305-321. doi: 10.1080/20932685.2018.1503556

Sheehan, B., Murphy, F., Kia, A. N., and Kiely, R. (2021). A quantitative bowtie cyber risk classification and assessment framework. J. Risk Res. 24, 1-20. doi: 10.1080/13669877.2021.1900337

Thormann, T. F., and Wicker, P. (2021). Willingness-to-pay for environmental measures in non-profit sport clubs. Sustainability 13:2841. doi: $10.3390 /$ su13052841

Tong, C., and Zhao, X. Y. (2019). Exploring users' motivations and behaviors on danmaku video sharing websites: a content analysis. Library Tribune. 39, 80-89. doi: 10.3969/j.issn.1002-1167.2019.06.010

Tsai, H., Lee, Y. P., and Ruangkanjanases, A. (2020). Understanding the effects of antecedents on continuance intention to gather food safety information on websites. Front. Psych. 11:579322. doi: 10.3389/fpsyg.2020.579322

Tudoran, A. A., and Olsen, S. O. (2017). Analyzing the returns of the first transaction satisfaction on intention to purchase and willingness to pay: evidence for new food products. J. Consumer Behav. 16, 372-386. doi: $10.1002 / \mathrm{cb} .1633$

Van der Heijden, H. (2003). Factors influencing the usage of websites: the case of a generic portal in The Netherlands. Inform. Manag. 40, 541-549. doi: 10.1016/s0378-7206(02)00079-4

Vladova, G., Ullrich, A., Bender, B., and Gronau, N. (2021). Students' Acceptance of Technology-Mediated Teaching-How It Was Influenced During the COVID-19 Pandemic in 2020: A Study from Germany. Frontiers in Psychology. 12, 69. doi: 10.3389/fpsyg.2021.636086

Wang, Z., and Scheepers, H. (2012). Understanding the intrinsic motivations of user acceptance of hedonic information systems: towards a unified research model. Commun. Assoc. Inform. Syst. 30:17. doi: 10.17705/1cais 03017

Wicker, P. (2011). Willingness-to-pay in non-profit sports clubs. Int. J. Sport Finan 6:155. Available online at: https://EconPapers.repec.org/RePEc:jsf:intjsf:v:6:y: 2011:i:2:p:155-169

Wicker, P., and Frick, B. (2020). Sustainable financing of elite athlete development: an empirical analysis of winter sports in austria. Sustainability 12:9664. doi: $10.3390 /$ su12229664

Wicker, P., Swierzy, P., and Breuer, C. (2018). Willingness-to-volunteer versus willingness-to-pay in sports clubs: how organizational capacity affects individual decisions. Europ. J. Sport Soc. 15, 332-351. doi: 10.1080/16138171.2018.1540325

Wicker, P., Whitehead, J. C., Johnson, B. K., and Mason, D. S. (2016). Willingnesto-pay for sporting success of football bundesliga teams. Contemp. Econ. Policy. 34, 446-462. doi: 10.1111/coep.12148

Wicker, P., Whitehead, J. C., Mason, D. S., and Johnson, B. K. (2017). Public support for hosting the olympic summer games in germany: the CVM approach. Urban Studies. 54, 3597-3614. doi: 10.1177/0042098016675085

$\mathrm{Wu}$, B., and Zhou, Y. N. (2017). Research on influencing factors of users' continuance intention toward taobao live streaming. E-Commerce Lett. 6, 44-53. doi: 10.12677/ECL.2017.63007

Yang, H., and Lee, H. (2018). Exploring user acceptance of streaming media devices: an extended perspective of flow theory. Inform. Syst. e-Business Manag. 16, 1-27. doi: 10.1007/s10257-017-0339-x

You, J. J., Jong, D., and Wiangin, U. (2020). Consumers' purchase intention of organic food via social media: the perspectives of task-technology fit and postacceptance model. Front. Psych. 11:579274. doi: 10.3389/fpsyg.2020.579274

Zawadzki, K. M. (2016). Public perception of intangible benefits and costs in the valuation of mega sports events: the case of Euro 2012 in Poland. Eastern Europ. Econ. 54, 437-458. doi: 10.1080/00128775.2016.1201689

Zhang, X., Kang, J., and Wu, Y. H. (2006). Study on the model and measurement of Football spectator satisfaction. J. Xidian Univer. 16, 37-41. doi: 10.16348/j.cnki.cn61-1336/c.2006.04.008

Zhang, Z., and Deng, Y. F. (2018). The factors affecting the willingness to pay for knowledge payment behavior. Mod. Educ. Techn. 28, 87-93. doi: 10.3969/j.issn.1009-8097.2018.11.013

Zhao, F., Ahmed, F., Hunt, V. J., Iqbal, M. K., and Qin, Y. (2020). Shaping behaviors through institutional support in british higher educational institutions: focusing on employees for sustainable technological change. Front. Psych. 12:584857. doi: 10.3389/fpsyg.2020.584857

Conflict of Interest: The authors declare that the research was conducted in the absence of any commercial or financial relationships that could be construed as a potential conflict of interest.

Copyright (C) 2021 Sun and Zhang. This is an open-access article distributed under the terms of the Creative Commons Attribution License (CC BY). The use, distribution or reproduction in other forums is permitted, provided the original author(s) and the copyright owner(s) are credited and that the original publication in this journal is cited, in accordance with accepted academic practice. No use, distribution or reproduction is permitted which does not comply with these terms. 